\title{
Drug-induced immune-mediated thrombocytopenia secondary to sunitinib in a patient with metastatic renal cell carcinoma: a case report
}

Zia Ansari ${ }^{*}$ and Mathew K George

\begin{abstract}
Introduction: Sunitinib is an oral multi-targeted tyrosine kinase inhibitor approved for first line treatment for metastatic renal cell carcinoma and imatinib-resistant metastatic gastrointestinal stromal tumors. Sunitinib administration can cause myelosuppression resulting in neutropenia and thrombocytopenia. Here we present the case of a patient with metastatic renal cell carcinoma who developed sunitinib-induced immune-mediated thrombocytopenia and who was treated with withdrawal of sunitinib and administration of intravenous immunoglobulin and steroids.

Case presentation: This case report describes a 70-year-old Aboriginal Australian with a diagnosis of metastatic renal cell carcinoma. Three weeks after the initiation of sunitinib he developed epistaxis and was admitted with thrombocytopenia (platelets $7 \times 109 / L$ ) which was found to be refractory to platelet transfusion. Sunitinib was stopped and he was treated with intravenous immunoglobulin and steroids. His platelet count rapidly improved and returned to baseline in three weeks. Only two cases of sunitinib-induced immune-mediated thrombocytopenia have been described in the literature.
\end{abstract}

Conclusion: Clinicians should have a high index of suspicion for the potential of immune-mediated thrombocytopenia after the initiation of multi-targeted tyrosine kinase inhibitors such as sunitinib. This is a diagnosis of exclusion and can be safely treated by drug withdrawal.

Keywords: Metastatic renal cell carcinoma, Sunitinib, Thrombocytopenia

\section{Introduction}

Sunitinib $\left(\right.$ Sutent ${ }^{\circledR}$ ) is an oral multi-targeted tyrosine kinase inhibitor. Sunitinib inhibits members of the splitkinase domain family of receptor tyrosine kinases (RTKs) including the vascular endothelial growth factor receptors (VEGFRs) types 1 and 2 (FLT1 and FLK1 or KDR); platelet-derived growth factor receptors alpha and beta (PDGFR-alpha and PDGFR-beta); the stem cell factor receptor c-KIT; and the FLT3 and RET kinases. Inhibition of these RTKs results in a reduction in tumor growth, progression, metastases and angiogenesis [1]. Clinically sunitinib is approved for the first line treatment of metastatic renal cell carcinoma (mRCC) and imatinib-resistant metastatic gastrointestinal stromal tumors. Reported toxicities

\footnotetext{
* Correspondence: Zia.Ansari@calvarymater.org.au

Department of Medical Oncology, Tamworth Rural Referral Hospital, Locked Mail Bag 9783, Tamworth, NEMSC NSW 2348, Australia
}

of sunitinib include fatigue, hypertension, diarrhea, vomiting, skin toxicity (hand and foot syndrome), neutropenia and thrombocytopenia [2]. Here we present the case report of a patient with $\mathrm{mRCC}$ who developed sunitinibinduced immune-mediated thrombocytopenia and recovered after the withdrawal of sunitinib and immunoglobulin and steroid support.

\section{Case presentation}

The patient is a 70-year-old Aboriginal Australian with a history of a left nephrectomy in 2005 for clear cell renal cell carcinoma as well as multiple co-morbidities including chronic obstructive airway disease, ischemic heart disease with coronary artery bypass graft, aortic valve replacement on warfarin and gastroesophageal reflux disease. His medications included fluticasone and salmeterol inhaler (250 and 50mcg respectively) two puffs twice a day, furosemide $20 \mathrm{mg}$ in the morning, atorvastatin $40 \mathrm{mg}$ 
at night, ranitidine $300 \mathrm{mg}$ in the morning, and paracetamol $1 \mathrm{~g}$ daily. Investigation for shortness of breath revealed multiple metastases in both lungs, the biopsy of which confirmed mRCC. There was no previous history of autoimmune disease, hematological disorder, liver disease, human immunodeficiency virus, or hepatitis B or hepatitis $C$ infection. His baseline full blood count revealed: hemoglobin $131 \mathrm{~g} / \mathrm{L}$, white blood cell count $6.4 \times 10^{9} / \mathrm{L}$ and platelets $294 \times 10^{9} / \mathrm{L}$. He was commenced on sunitinib $50 \mathrm{mg} /$ day. The patient did not take any new medications, herbal or over the counter drugs since his commencement of sunitinib. There was no evidence of liver metastases.

A routine full blood count two weeks post-treatment showed a decline in his platelets to $129 \times 10^{9} / \mathrm{L}$, however, his hemoglobin was $161 \mathrm{~g} / \mathrm{L}$ and white blood cell count was $4.9 \times 10^{9} / \mathrm{L}$. In the third week he developed epistaxis and was admitted to hospital. His platelets dropped to $7 \times 10^{9} / \mathrm{L}$ and his international normalized ratio (INR) was 2.4. This was reversed with an intravenous vitamin $\mathrm{K}$ injection. His sunitinib and warfarin were stopped. The epistaxis stabilized with nasal packing and he received a platelet transfusion. His thrombocytopenia did not respond and his platelet count dropped further to $1 \times 10^{9} / \mathrm{L}$.

On clinical examination there was evidence of oropharyngeal petechiae, epistaxis and peripheral ecchymoses. There was no fever, lymphadenopathy, hepatosplenomegaly or neurological signs. Laboratory investigations included normal renal function tests, electrolytes and stable liver function tests. Coagulation screening showed his INR had reversed to 1.1 after intravenous vitamin $\mathrm{K}$, prothrombin time 12 seconds (11 to 15 ), activated partial thromboplastin time 24 seconds (23 to 38 ) and fibrinogen $3.7 \mathrm{~g} / \mathrm{L}$ (2.0 to 4.0$)$. Peripheral blood film showed thrombocytopenia and no evidence of schistocytosis, spherocytosis or dysplasia. There was no evidence of hemolysis.

Disseminated intravascular coagulation and thrombotic microangiopathy were ruled out as possible causes of sunitinib-mediated thrombocytopenia by the results of the above investigations. Platelet-bound immunoglobulin and a bone marrow aspirate were not performed when discussed with a hematologist, and the diagnosis of exclusion, sunitinib-induced immune-mediated thrombocytopenia, was made. The patient was treated with intravenous immunoglobulin $27.5 \mathrm{~g}(0.4 \mathrm{~g} / \mathrm{kg})$ once daily for five days with prednisolone $50 \mathrm{mg}$ once a day. His platelet count rapidly improved to $103 \times 10^{9} / \mathrm{L}$ and returned to a baseline of $259 \times 10^{9} / \mathrm{L}$ after three weeks.

Normalization of this patient's platelet count following withholding of sunitinib is consistent with the diagnosis of immune-mediated thrombocytopenia secondary to sunitinib.

\section{Discussion}

Drug-induced immune-mediated thrombocytopenia is thought to be a result of antibody production in the presence of a sensitizing medication, with the antibodies targeting epitopes on the platelet surface, subsequently leading to the clearance of the antibody-coated platelets by the mononuclear phagocytic system. It takes five to seven days of exposure to produce sensitization in a patient given the drug for the first time. Although druginduced thrombocytopenia is uncommon, it can have devastating, and even fatal, consequences that can usually be prevented simply by discontinuing the causative drug. It is therefore important that clinicians have a general understanding of this condition and the drugs that can cause it. Chemotherapeutic and immunosuppressive agents typically cause thrombocytopenia by suppressing hematopoiesis; they can also cause immune-mediated thrombocytopenia [3]. Drug-induced thrombocytopenia should be suspected, therefore, in patients treated with such drugs if there is an acute drop in the platelet level after exposure.

Thrombotic microangiopathy is another cause of sunitinib-mediated thrombocytopenia, reported by Kapiteijn et al. [4]. Sunitinib is a tyrosine kinase inhibitor that targets VEGFR-2 and PDGFR-beta, which are both the major expression subtypes of VEGFR and PDGFR in capillary vasculature. It is hypothesized that sunitinib acts via direct anti-VEGFR and anti-PDGFR effects that result in damage of the capillary endothelium [4].

Sunitinib has been associated with other autoimmune disorders such as hypothyroidism; therefore, the possibility of an immunologic phenomenon to account for sunitinib-induced immune-mediated thrombocytopenia is reasonable $[5,6]$. However, the exact mechanism by which sunitinib induces an immune-mediated thrombocytopenia is unknown. In a phase III trial of metastatic renal cell cancer patients, Motzer et al. reported some grade of thrombocytopenia in 65 of 375 patients randomized to sunitinib treatment, with eight of the 65 (12\%) having grade 3 thrombocytopenia [7].

Renal cell carcinoma is also associated with immunemediated thrombocytopenia $[8,9]$. Therefore, we cannot rule out the possibility that the immune-mediated thrombocytopenia was related to renal cell carcinoma. However, in our case, sunitinib administration after the diagnosis of renal cell carcinoma resulting in thrombocytopenia resolving completely upon drug withdrawal is consistent with sunitinib-induced immune-mediated thrombocytopenia.

There have been two cases of sunitinib-induced immune-mediated thrombocytopenia reported to date. In both cases patients were treated with intravenous immunoglobulin $1 \mathrm{~g} / \mathrm{kg}$ over two days and intravenous tranexamic acid $[10,11]$. 


\section{Conclusion}

In this case thrombocytopenia following the initiation of the multi-targeted tyrosine kinase inhibitors, sunitinib, was safely treated by drug withdrawal. When treating patients with these agents clinicians should have a high index of suspicion for the potential of immune-mediated thrombocytopenia which is a diagnosis of exclusion.

\section{Consent}

Written informed consent was obtained from the patient for publication of this case report. A copy of the written consent is available for review by the Editor-in-Chief of this journal.

\section{Competing interests}

The authors declare that they have no competing interests.

\section{Authors' contributions}

ZA and MG were both involved in the patient diagnosis and management. ZA conducted the literature review and carried out the review of the patient's medical record. MG participated in the preparation of the manuscript and revised the article for intellectual content details. Both authors read and approved the final manuscript.

\section{Authors' information}

ZA is an advanced trainee in Medical Oncology at Tamworth Rural Referral Hospital. MG is a Medical Oncologist at Tamworth Rural Referral Hospital.

\section{Acknowledgements}

We thank Mrs Sana Ansari for drafting and formatting the manuscript and Dr Philip Dalley for proof reading the manuscript.

Received: 10 November 2012 Accepted: 24 January 2013

Published: 26 February 2013

\section{References}

1. Chow Laura QM, Eckhardt SG: Sunitinib: from rational design to clinical efficacy. J Clin Oncol 2007, 25(7):884-896.

2. Faivre S, Delbaldo C, Vera K, Robert C, Lozahic S, Lassau N, Bello C, Deprimo S, Brega N, Massimini G, Armand JP, Scigalla P, Raymond E: Safety, pharmacokinetic, and antitumor activity of SU11248, a novel oral multitarget tyrosine kinase inhibitor, in patients with cancer. $J$ Clin Oncol 2006, 24:25-35.

3. Aster R, Bougie D: Drug-induced immune thrombocytopenia. N Eng J Med 2007, 357:580-587

4. Kapiteijn E, Brand A, Kroep J, Gelderblom H: Sunitinib induced hypertension, thrombotic microangiopathy and reversible posterior leukencephalopathy syndrome. Ann Oncol 2007, 18(10):1745-1747.

5. Brown R: Tyrosine kinase inhibitor-induced hypothyroidism: incidence, etiology, and management. Target Oncol 2011, 6(4):217-226.

6. Sella A, Hercbergs A, Hanovich E, Kovel S: Does sunitinib-induced hypothyroidism play a role in the activity of sunitinib in metastatic renal cell carcinoma? Int J Exp Clin Chemother 2012, 58(3):200-205.

7. Motzer RJ, Hutson TE, Tomczak P, Michaelson MD, Bukowski RM, Rixe O, Oudard S, Negrier S, Szczylik C, Kim ST, Chen I, Bycott PW, Baum CM, Figlin RA: Sunitinib versus interferon alfa in metastatic renal-cell carcinoma. $N$ Eng J Med 2007, 356(2):115-124.

8. Yoshinaga A, Hayashi T, Ohno R, Yoshida S, Ishii N, Terao T, Watanabe T, Yamada T: A case of renal cell carcinoma associated with idiopathic thrombocytopenic purpura. Hinyokika Kiyo 2005, 51(6):377-380.

9. Klimberg I, Drylie D: Renal cell carcinoma and idiopathic thrombocytopenic purpura. Urology 1984, 23(3):293-296.
10. Trinkaus M, Trudeau M, Callum J: Drug-induced immune thrombocytopenic purpura secondary to sunitinib. Curr Oncol 2008, 15(3):152-154.

11. Tunio M, Ahmad S, Fareed M, AlAsir M: Sunitinib induced immune thrombocytopenia in patient with metastatic renal cell carcinoma. J Solid Tumors 2011, 1(2):80-82.

doi:10.1186/1752-1947-7-54

Cite this article as: Ansari and George: Drug-induced immune-mediated thrombocytopenia secondary to sunitinib in a patient with metastatic renal cell carcinoma: a case report. Journal of Medical Case Reports 2013 7:54

\section{Submit your next manuscript to BioMed Central and take full advantage of:}

- Convenient online submission

- Thorough peer review

- No space constraints or color figure charges

- Immediate publication on acceptance

- Inclusion in PubMed, CAS, Scopus and Google Scholar

- Research which is freely available for redistribution 